\title{
Population-based study of capsular warning syndrome and prognosis after early recurrent TIA
}

Nicola L.M. Paul, MRCP

Michela Simoni, MRCP

Arvind Chandratheva, MRCP, PhD

Peter M. Rothwell, MD, PhD, FRCP, FMedSci

Correspondence \& reprint requests to Prof. Rothwell: peter.rothwell@clneuro.ox.ac.uk

\section{ABSTRACT}

Objective: Many guidelines recommend emergency assessment for patients with $\geq 2$ TIAs within 7 days, perhaps in recognition of the capsular warning syndrome. However, it is unclear whether all patients with multiple TIAs are at high early risk of stroke and whether treatable underlying pathologies are more prevalent in this group.

Methods: We studied clinical characteristics, Trial of Org 10172 in Acute Stroke Treatment (TOAST) classification, and risk of stroke in 1,000 consecutive patients with incident and recurrent TIAs in a prospective, population-based study (Oxford Vascular Study).

Results: Of 1,000 patients with TIAs, 170 had a further TIA within 7 days (105 within 24 hours). Multiple TIAs were not associated with carotid stenosis or atrial fibrillation, and much of the 10.6\% (95\% confidence interval [CI] 6.5-15.9) risk of stroke during the 7 days after the first TIA was due to patients with small-vessel disease (SVD) etiology (10 of 24 vs 8 of 146, odds ratio $[\mathrm{OR}]=12.3,95 \% \mathrm{Cl} 3.7-41.9, \mathrm{p}<0.0001$ ), particularly those with motor weakness (i.e., capsular warning syndrome) compared with hemisensory events (9 of 15 [60\%], 95\% Cl 35.3-84.7 vs 1 of 9 [11.1\%], 95\% Cl 0-31.7, $p=0.03)$. The 7-day risk of stroke after a recurrent TIA was similar to the risk after a single TIA in patients with non-SVD TIA (8 of 146 [5.5\%] vs 76 of 830 [9.2\%], OR $=0.58,95 \% \mathrm{Cl} 0.25-1.3, p=0.20)$. Of the 9 patients with stroke after a capsular warning syndrome, all had the recurrent TIA within 24 hours after the first TIA, and the subsequent stroke occurred within 72 hours of the second TIA in 8 . The ABCD2 scores of all preceding TIAs were $\geq 4$ in all 9 patients with capsular warning syndrome before stroke.

Conclusions: Capsular warning syndrome is rare (1.5\% of TIA presentations) but has a poor prognosis (7-day stroke risk of 60\%). Otherwise, recurrent TIA within 7 days is not associated with a greater stroke risk than that after a single TIA. Neurology ${ }^{\circledR}$ 2012;79:1356-1362

\section{GLOSSARY}

$\mathbf{C I}=$ confidence interval; GP = general practitioner; OR = odds ratio; OXVASC = Oxford Vascular Study; SVD = small-vessel disease; TOAST $=$ Trial of Org 10172 in Acute Stroke Treatment.

The risk of stroke after TIA is highest within the first 7 days. ${ }^{1-8}$ Individual risk can be predicted to some extent by the use of clinical scores such as the ABCD2 score. ${ }^{9}$ The occurrence of recurrent or dual TIAs has been proposed as an addition to the ABCD2 score to improve early stroke risk prediction after TIA. ${ }^{10}$ Many guidelines also recommend urgent evaluation for patients with $\geq 2$ TIAs within 7 days, ${ }^{11-17}$ perhaps in recognition of the capsular warning syndrome. In the classic description of the capsular warning syndrome, multiple, stereotyped motor TIAs precede capsular infarction, ${ }^{18,19}$ probably as a consequence of hemodynamic compromise or thrombosis within a small, single penetrating artery or proximal middle cerebral artery stenosis. ${ }^{19-21}$ It is not certain whether all patients with recurrent TIAs are at high early risk of stroke or whether the capsular warning syndrome mainly accounts for the overall increased risk. Moreover, the prognosis of capsular warning syndrome itself may have changed

From the Stroke Prevention Research Unit (N.L.M.P., M.S., A.C., P.M.R.), Nuffield Department of Clinical Neurosciences, John Radcliffe Hospital, Oxford, UK.

Study funding: The Oxford Vascular Study is funded by the UK Medical Research Council, Dunhill Medical Trust, Stroke Association, BUPA Foundation, National Institute for Health Research (NIHR), Thames Valley Primary Care Research Partnership, NIHR Biomedical Research Centre, Oxford, and the Wellcome Trust.

Go to Neurology.org for full disclosures. Disclosures deemed relevant by the authors, if any, are provided at the end of this article. 
since the original hospital-based studies of patients presenting in the 1980 s and $1990 s^{18,19}$ and may also be systematically different in population-based studies. It is also not certain to what extent other treatable underlying pathologic conditions, such as carotid stenosis or atrial fibrillation, are overrepresented in patients with multiple TIAs. We addressed these issues in the first prospective, populationbased study of the incidence, prognosis, and outcomes of all incident and recurrent TIAs and strokes in Oxfordshire, UK (Oxford Vascular Study [OXVASC]).

METHODS OXVASC is a prospective, population-based study of all strokes and TIAs in 91,105 individuals of all ages registered with 63 general practitioners (GPs) in Oxfordshire, UK. The study methods have been described elsewhere. ${ }^{22,23}$ In brief, multiple overlapping methods of hot and cold pursuit were used to achieve near-complete ascertainment of all individuals presenting to medical attention with TIA or stroke $e^{22-24}$ These include the following:

1. A 7-day, open-access TIA service to which participating GPs and the local accident and emergency department send all individuals with suspected TIA or minor stroke whom they would not normally admit to the hospital, with emergency provision on weekends supplementing a weekday clinic.

2. Daily searches of admissions to the stroke unit, medical, neurology, and other relevant wards.

3. Daily searches of the local accident and emergency and eye hospital attendance register.

4. Monthly computerized searches of GP diagnostic coding and hospital discharge codes.

5. Monthly searches of all cranial and carotid imaging studies performed in local hospitals.

6. Monthly reviews of all death certificates and coroner reports.

All patients presenting with TIAs were asked about symptoms of TIA within the previous 90 days. Event characteristics and risk factors were recorded, and patients underwent brain imaging with CT or MRI as appropriate. All cases were subsequently reviewed by the study senior neurologist (P.M.R.) and classified as TIA or other condition using standard definitions. ${ }^{22,23}$ We excluded stroke patients in whom it was impossible to obtain a definite history of preceding TIAs because they were aphasic, confused, or unconscious. Patients were followed up face to face at 30 days and 6 months by a study nurse or physician, recurrent symptoms were recorded, and disability was assessed with the modified Rankin scale. All recurrent events that received medical attention would also be identified acutely by ongoing daily case-ascertainment within OXVASC. All patients with recurrent events were reassessed by a study physician and reviewed by P.M.R. Etiologic classification of events was performed according to the Trial of Org 10172 in Acute Stroke Treatment (TOAST) classification once investigations were complete. ${ }^{25}$ This article includes the first 1,000 consecutive patients with TIAs from April 1, 2002, to August 15, 2011.

Analysis. We restricted analysis to the risk of recurrent events after the first TIA in the study period (index TIA). We determined the risk of recurrent TIA and stroke within 90 days of the index TIA, including patients who did not seek medical attention for the initial symptoms but presented after a recurrent TIA or stroke. A recurrent TIA was defined as a new neurologic symptom of less than 24 hours' duration in a patient in whom the initial symptoms had completely resolved. In patients who had multiple recurrent events, the end point was the first recurrence after the index TIA. A recurrent stroke was defined as a new persistent neurologic symptom in a patient in whom the initial symptoms had already substantially or fully resolved. The 7-day risk of stroke after the recurrent TIA was determined in relation to the $\mathrm{ABCD} 2$ score and TOAST subtype. A lacunar (or small-vessel disease [SVD]) TIA was diagnosed if the following criteria were fulfilled: 1) the presence of a) unilateral motor or sensory disturbance of at least 2 of 3 body parts (face, arm, leg) in the absence of cortical dysfunction presumed due to subcortical ischemia, b) ataxic hemiparesis, or c) clumsy hand dysarthria syndrome and 2) the presence of lacunar infarct on diffusionweighted imaging (in patients with symptom duration $<4$ hours or 3) absence of other TOAST etiologies.

We defined capsular warning syndrome as recurrent, motor lacunar TIAs within 7 days.

Standard protocol approvals, registrations, and patient consents. OXVASC is approved by our local ethics committee. All patients provided written consent and were seen by study physicians as soon as possible after their initial presentation.

RESULTS Complete baseline data and follow-up to 90 days were available for all 1,000 consecutive, first TIAs (table 1). The mean (range) age was 73 (2499) years with 327 (33\%) patients aged older than 80 years. A total of 940 patients were referred to secondary care in Oxford, and 684 (73\%) to the TIA clinic (32 patients had their event on holiday and 28 were managed by their GP only). Of 871 patients with cerebral TIAs referred to secondary care, 828 (95\%) had brain imaging; the majority had CT (703 [85\%]) as first-line imaging, and $125(15 \%)$ had MRI. For those without brain imaging, reasons were patient condition $(n=22)$, diagnostic uncertainty at initial assessment $(n=12)$, and patient refusal $(n=9)$.

A total of $246(25 \%)$ patients had a recurrent event at 7 days (table 2), with the first recurrence being a TIA in 170 patients $(17.0 \%, 95 \%$ confidence interval [CI $14.6-19.4)$ and stroke in 76 cases (9.2\%, 7.2-11.2). Patients with recurrent TIAs were younger ( $p=0.007)$ (table 1$)$, less likely to have had a previous stroke $(p=0.02)$ or to be taking antihypertensive drugs $(p=0.04)$, and more likely to have intracranial vascular imaging $(p<0.001)$, but no more likely to have atrial fibrillation or $\geq 50 \%$ symptomatic carotid stenosis (17 of 90 vs 186 of 442 , $p=$ 1.0 , in those with carotid territory events) than in those with a single TIA. Of all recurrent TIAs within 7 days, 105 (62\%) occurred within 24 hours and 136 (80\%) within 48 hours. The second TIA occurred before the patient sought medical attention in 141 patients (83\%). TOAST subtype was not associated with a risk of recurrent TIA (table 1). 


\begin{tabular}{|c|c|c|c|}
\hline \multicolumn{4}{|c|}{ Table 1 Baseline characteristics of all patients } \\
\hline & Single TIA $(n=830)$ & Recurrent TIA $(n=170)$ & p Value \\
\hline Age, y, mean (SD) & $72.8(13.4)$ & $69.7(13.7)$ & 0.007 \\
\hline Male sex, $\mathrm{n}(\%)$ & $384(46.3)$ & $89(52.4)$ & 0.15 \\
\hline Closest systolic BP after TIA, mm Hg, mean (SD) & $151.3(28.0)$ & $151.7(23.6)$ & 0.87 \\
\hline Closest diastolic BP after TIA, mm Hg, mean (SD) & $82.0(14.1)$ & $83.3(12.6)$ & 0.26 \\
\hline Hypertension, $\mathrm{n}(\%)$ & $460(55.4)$ & $84(49.4)$ & 0.18 \\
\hline Diabetes, $\mathrm{n}(\%)$ & 107 (12.9) & 27 (15.9) & 0.32 \\
\hline Angina or myocardial infarction, $\mathrm{n}(\%)$ & $152(18.3)$ & 29 (17.1) & 0.74 \\
\hline Peripheral vascular disease, $\mathrm{n}(\%)$ & $42(5.1)$ & 5 (2.9) & 0.32 \\
\hline Atrial fibrillation, $\mathrm{n}(\%)$ & $131(15.8)$ & $25(14.7)$ & 0.82 \\
\hline Current smoker, $\mathrm{n}(\%)$ & $103(12.4)$ & $23(13.5)$ & 0.70 \\
\hline Previous TIA, $n$ (\%) & 110 (13.3) & 19 (11.2) & 0.53 \\
\hline Previous stroke, $\mathrm{n}(\%)$ & $86(10.4)$ & $8(4.7)$ & 0.02 \\
\hline \multicolumn{4}{|l|}{ Prior treatment } \\
\hline Antiplatelet/anticoagulant, $\mathrm{n}(\%)$ & 319 (38.4) & $58(34.1)$ & 0.30 \\
\hline Statin, $n(\%)$ & $203(24.5)$ & $45(26.5)$ & 0.63 \\
\hline Antihypertensive, $\mathrm{n}(\%)$ & $460(55.4)$ & $79(46.5)$ & 0.04 \\
\hline Carotid territory, $\mathrm{n}(\%)$ & $513(61.8)$ & $98(57.6)$ & 0.31 \\
\hline Carotid imaging, $n(\%)^{a}$ & 716 (86.3) & $158(92.9)$ & 0.02 \\
\hline Intracranial vascular imaging, $\mathrm{n}(\%)$ & $272(32.8)$ & $88(51.8)$ & 0.001 \\
\hline \multicolumn{4}{|l|}{ TOAST } \\
\hline CE & $136(16.4)$ & $22(12.9)$ & 0.30 \\
\hline LAA & $106(12.8)$ & 30 (17.6) & 0.11 \\
\hline SVD & 85 (10.2) & $24(14.1)$ & 0.09 \\
\hline Undetermined & $391(47.1)$ & 78 (48.9) & 0.80 \\
\hline Unknown/multiple/other & $16(9.4)$ & $112(13.5)$ & 0.17 \\
\hline
\end{tabular}

Abbreviations: $\mathrm{BP}=$ blood pressure; $\mathrm{CE}=$ cardioembolism; LAA = large artery arteriosclerosis; SVD = small-vessel disease; TOAST $=$ Trial of Org 10172 in Acute Stroke Treatment.

a Includes patients with vertebrobasilar events.

In those with recurrent TIAs, stroke risk after the first TIA was $5.9 \%(95 \%$ CI $2.4-9.4, \mathrm{n}=10)$ in the first 48 hours, $10.6 \%$ at 7 days $(5.9-15.3, \mathrm{n}=18)$, $14.1 \%$ at 30 days $(8.8-19.4, \mathrm{n}=24)$, and $14.7 \%$ $(9.4-20, \mathrm{n}=25)$ at 90 days. The 7 -day stroke risk after recurrent TIA was similar to the risk after a single TIA ( 18 of 170 vs 76 of $830, p=0.56$ ), and risks were also similar when stratified by $\mathrm{ABCD} 2$ score (table 2). In contrast to the risk of recurrent TIA, which did not vary according to TOAST subtype, the 7 day stroke risk was highest after recurrent TIAs of the SVD subtype ( 10 of 24 vs 8 of 146 , odds ratio $[\mathrm{OR}]=12.3,95 \% \mathrm{CI} 3.7-41.9, p<0.0001$ ). For all other TOAST subtypes, 7-day stroke risk was no different after recurrent TIAs compared with that after a single TIA ( 8 of 146 [5.5\%] vs 76 of 830 [9.2\%], OR $=0.58,0.25-1.3, p=0.20$ ). Thus, recurrent TIAs of the SVD type were associated with a particularly high 7-day stroke risk of $42 \%$ (10 of 24, 21.9-61.5), and risks were highest after recurrent motor TIAs than after recurrent sensory TIAs (9 of 15 [60\%] vs 1 of 9 [11.1\%], $p=0.03$ ) (figure 1 ). However, if strokes due to TIAs of SVD etiology are excluded, the 7-day stroke risk after a recurrent TIA is low (8 of 146 (5.5\%), 1.8-9.2) (figure 1). At 30 days, the risk of stroke in those with a recurrent TIA and $\geq 50 \%$ symptomatic carotid/vertebral stenosis or atrial fibrillation tended to be higher than that in those non-SVD recurrent TIAs of undetermined etiology (9 of 41 [22.0\%], 9.3-34.7 vs 6 of 114 [5.3\%], $1.2-9.4, p=0.002$ ) (figure 2). Of 13 patients with non-SVD recurrent TIAs and $\geq 50 \%$ symptomatic carotid stenosis, only 1 had a carotid endarterectomy within 7 days.

Of 24 patients with recurrent TIAs of the SVD subtype, the main features were motor weakness in 15 patients (12 with hemiparesis, 2 with ataxic hemiparesis, and 1 with slurred speech) and heminumbness in 9 patients. Of 146 patients with recurrent TIAs of the non-SVD subtype, only 7 had hemiweakness without cortical symptoms; the etiologies in these patients were large artery arteriosclerosis 


\begin{tabular}{|c|c|c|c|c|c|c|}
\hline \multirow[t]{2}{*}{ Table 2} & \multicolumn{6}{|c|}{$\begin{array}{l}\text { Seven-day stroke risk after single and recurrent TIA stratified by ABCD2 score of the first TIA and } \\
\text { TOAST classification }\end{array}$} \\
\hline & $\begin{array}{l}\text { No. single } \\
\text { TIA }\end{array}$ & $\begin{array}{l}\text { No. } \\
\text { strokes }\end{array}$ & $\begin{array}{l}\text { 7-day stroke risk, } \\
\%(95 \% \mathrm{CI})\end{array}$ & $\begin{array}{l}\text { No. recurrent } \\
\text { TIAs }\end{array}$ & $\begin{array}{l}\text { No. } \\
\text { strokes }\end{array}$ & $\begin{array}{l}\text { 7-day stroke risk, \% } \\
(95 \% \mathrm{Cl})\end{array}$ \\
\hline \multicolumn{7}{|l|}{$A B C D 2$ score } \\
\hline 0 & 3 & 0 & 0 & 1 & 0 & 0 \\
\hline 1 & 48 & 3 & $6.2(0-13.1)$ & 19 & 0 & 0 \\
\hline 2 & 115 & 7 & $6.1(1.8-10.4)$ & 36 & 3 & $8.3(0-17.3)$ \\
\hline 3 & 152 & 10 & $6.6(2.7-10.5)$ & 39 & 3 & $7.7(0-16.1)$ \\
\hline 4 & 187 & 14 & 7.5 (3.8-11.2) & 34 & 3 & $8.8(0-18.4)$ \\
\hline 5 & 173 & 14 & $8.1(4.0-12.2)$ & 27 & 5 & 18.5 (3.8-33.2) \\
\hline 6 & 133 & 26 & $19.5(12.8-26.2)$ & 11 & 3 & $27.3(1-53.6)$ \\
\hline 7 & 19 & 2 & $10.5(0-24.2)$ & 3 & 1 & $33.3(0-86.6)$ \\
\hline ABCD score $<4$ & 318 & 20 & $6.3(3.6-9.0)$ & 95 & 6 & $6.3(1.4-11.2)$ \\
\hline$A B C D$ score $\geq 4$ & 512 & 56 & $10.9(8.2-13.6)$ & 75 & 12 & $16.0(7.8-24.2)$ \\
\hline \multicolumn{7}{|l|}{ TOAST } \\
\hline CE & 136 & 16 & $11.8(9.8-13.8)$ & 22 & 2 & $9.1(0-21.12)$ \\
\hline LAA & 106 & 13 & $12.3(6.0-18.6)$ & 30 & 3 & $10.0(0-20.8)$ \\
\hline SVD & 85 & 17 & $20.0(11.6-28.4)$ & 24 & 10 & $41.7(21.9-61.5)$ \\
\hline Undetermined & 391 & 15 & $3.8(1.8-5.8)$ & 78 & 1 & $1.3(0-3.8)$ \\
\hline Unknown & 74 & 8 & $10.8(3.7-17.9)$ & 6 & 1 & $16.7(0-46.5)$ \\
\hline Multiple/other & 38 & 7 & $18.4(6.1-30.7)$ & 10 & 1 & $10.0(0-28.6)$ \\
\hline Total patients & 830 & 76 & $9.2(7.2-11.2)$ & 170 & 18 & $10.6(5.9-15.3)$ \\
\hline
\end{tabular}

Abbreviations: $\mathrm{CE}=$ cardioembolism; $\mathrm{Cl}=$ confidence interval; $\mathrm{LAA}=$ large artery arteriosclerosis; $\mathrm{SVD}=$ small-vessel disease; TOAST $=$ Trial of Org 10172 in Acute Stroke Treatment.

(LAA) $(\mathrm{n}=3)$, cardioembolism $(\mathrm{n}=2)$, multiple $(\mathrm{n}=1)$, and other $(\mathrm{n}=1)$. Of 10 patients with stroke after recurrent lacunar SVD TIAs, all had the recurrent TIAs within 24 hours after the first TIA (median time to the recurrent TIA 2.3 hours, SD 9.4).

\section{Figure 1 Seven-day stroke risk after the first TIA in single and recurrent TIA} of lacunar and nonlacunar type

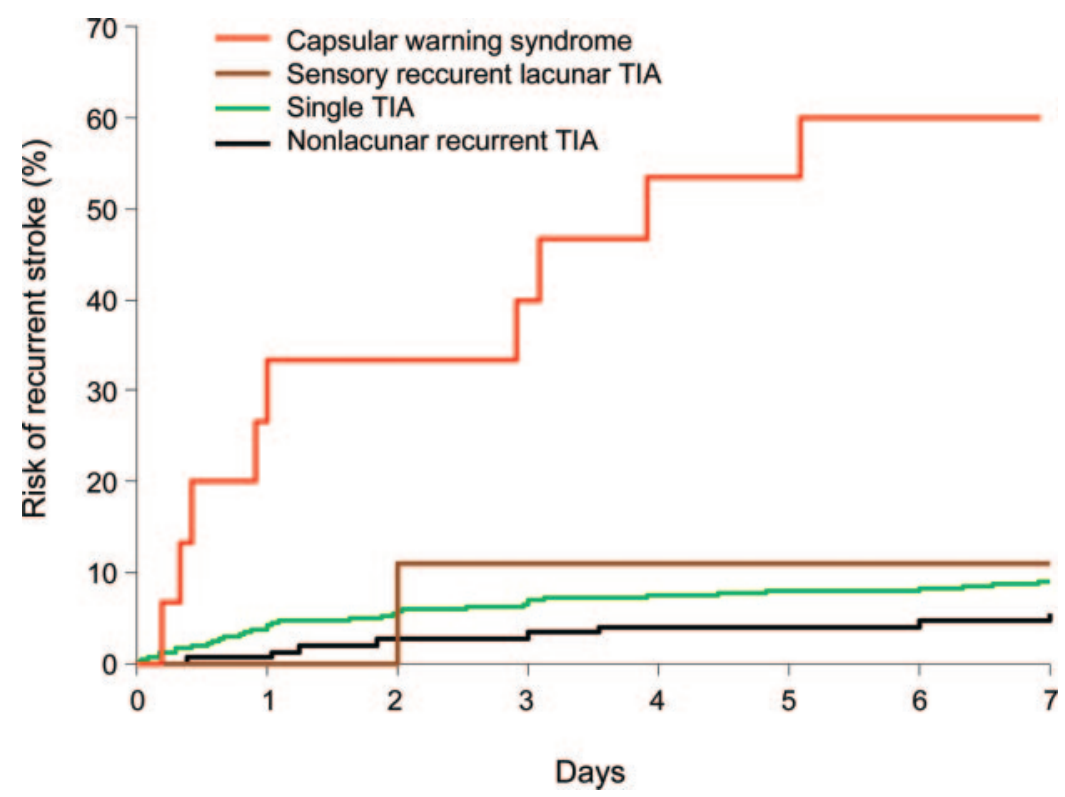

The subsequent stroke occurred within 24 hours of the second TIA in 5 patients and within 72 hours in 9 patients (median time to stroke 29.5 hours, SD 37.7). Nine of the 10 patients had motor weakness as a feature of the recurrent TIA (8 with hemiparesis and 1 with slurred speech) and only 1 had heminumbness, such that the ABCD2 score of all TIAs before stroke was $\geq 4$ in 9 patients.

Of 15 patients with recurrent motor lacunar TIAs (capsular warning syndrome), the 7-day stroke risk was $60 \%(95 \%$ CI $35.3-84.7, \mathrm{n}=9)$, with no strokes at 8-90 days. Ten of 15 patients presented to medical attention before any stroke ( 5 to GPs, 4 to the accident and emergency department, and 1 to a doctor while on holiday) and 5 presented after a subsequent stroke. Among the 10 patients who presented before any stroke, the risk of progression to stroke appeared to be lower in those given an immediate loading dose of an antiplatelet drug ( 0 of 4 vs 4 of $6, p=0.08)$, either starting aspirin $(\mathrm{n}=3)$ or adding clopidogrel to premorbid aspirin $(n=1)$. Of the 9 patients with capsular warning syndrome stroke, the median modified Rankin scale score at 1 month after stroke was 2 (range 1-4).

DISCUSSION Recurrent TIA has been incorporated into guidelines as an indication for urgent sec- 
Figure 2 Thirty-day stroke risk after the first TIA in those with recurrent TIA and capsular warning syndrome, $\geq 50 \%$ symptomatic carotid stenosis, atrial fibrillation (AF), or neither of these etiologies

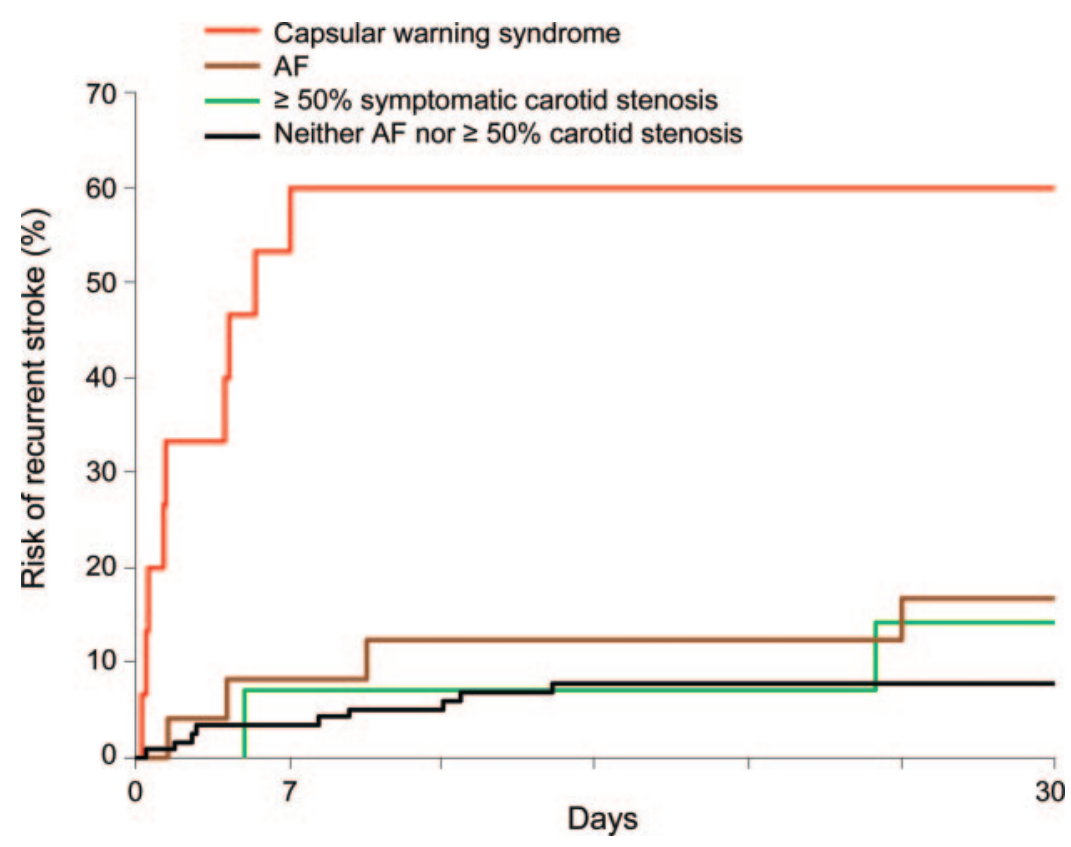

ondary prevention, ${ }^{11-17}$ and it has been proposed that it should be included as a variable in prognostic scores. ${ }^{10}$ However, there are limited published data on whether all those with multiple TIAs are at high risk of recurrent stroke or whether this group differs in terms of treatable underlying pathologies. We have shown the early stroke risk after a recurrent TIA is similar to that after a single TIA in our population, other than in the case of the capsular warning syndrome, and that the prevalence of atrial fibrillation and large-artery stenosis is no greater. Indeed, in patients with multiple non-SVD TIAs, the early risk of stroke tended to be lower than that after a single TIA.

In our study, the 7-day risk of recurrent TIA was high at $17 \%$, which appears to be consistent with previous studies. ${ }^{10,26,27}$ However, reports of the prognostic significance of recurrent TIAs have been less consistent. In an emergency department cohort of 1,707 patients, the 90-day stroke risk after a recurrent TIA was not greater than that after a single TIA. ${ }^{28}$ In another hospital-based study of 113 patients with TIAs, progression or fluctuation of symptoms was an independent predictor of stroke. ${ }^{26}$ However, when patients with multiple attacks at presentation were analyzed separately, there was no significant difference in stroke risk. ${ }^{26}$ In a recent analysis of pooled data from 2,654 patients with TIAs, $\geq 2$ TIAs within 7 days occurred in $19.4 \%$ and was associated with higher stroke risk $(\mathrm{OR}=5.0,95 \% \mathrm{CI}$ 2.76-9.06). ${ }^{10}$ However, no previous studies have determined the extent to which prognostic significance is dependent on the underlying etiology of recurrent TIAs.

In our study, early stroke risk was highest after a single or recurrent TIA of SVD etiology. Previous studies have shown that the large-artery stenosis subtype is associated with high recurrent stroke risk after TIA or stroke $\mathrm{e}^{27,29,30}$ but have tended to underestimate the risk of stroke after SVD events by including patients presenting with lacunar stroke rather than lacunar TIA. Although capsular warning syndrome is rare (only $1.5 \%$ of TIA presentations in our study), the early risk of stroke in previous studies has been very high. ${ }^{18,19}$ Our results show that this poor prognosis still applies today. In contrast to capsular warning syndrome, however, the risk of stroke after recurrent TIAs of other etiologies was much lower in our study. The current emphasis in guidelines on greater urgency of assessment of all patients with multiple vs single TIAs may not be justified by their stroke risk.

The emphasis on recurrent TIAs in management guidelines and in prognostic scores could still be justified, however, if they were particularly associated with treatable pathologic conditions. However, we found no excess of atrial fibrillation or carotid stenosis in patients with multiple TIAs. Moreover, specific treatments for capsular warning syndrome are lacking, although thrombolysis, hydration, blood pressure elevation, and dual antiplatelet and anticoagulant treatment have been shown to be beneficial in case reports. ${ }^{31-35}$

Our results show that despite improvements in processes of care, the prognosis of capsular warning syndrome is similar to that when it was first described in the 1980s. The trend toward a reduced risk of early stroke in patients given an immediate loading dose of antiplatelet drugs is encouraging, and this approach is probably justified despite the lack of trial data.

In our study, less than half of patients with capsular warning syndrome presented to medical attention before recurrent stroke, highlighting the continued need for public education on TIAs. However, we also found that the high risk of stroke persists beyond 48 hours, such that randomized treatment trials might be feasible nevertheless.

Our study had some potential limitations. First, our estimate of stroke risk in the acute phase may not be completely precise because an unknown proportion of patients with TIAs and minor strokes will never seek medical attention. However, this bias is likely to be somewhat smaller after a second event, with patients probably being less likely to ignore 2 events. Second, our analysis of stroke risk after a recurrent TIA was based on only 18 stroke outcomes. 
Although this is more than the 12 stroke outcomes after multiple TIAs in the Californian cohort, ${ }^{28}$ further studies would help confirm or refute our findings. Third, the intensity and timing of secondary prevention may have varied according to treatment setting, causing a difference in the timing of recurrent events. However, $73 \%$ of our patients were seen in the EXPRESS clinic, ${ }^{36}$ in which secondary prevention was initiated at time of assessment, and only 1 patient had a carotid endartectomy with 7 days; therefore, the effect of treatment setting is likely to be small. Fourth, the low stroke risk after pure sensory lacunar TIAs may be due to events of nonvascular origin, a limitation also present in previous studies of recurrent TIA. ${ }^{28}$ However, even if many of our patients had nonischemic events, the stroke risk would still be low. Therefore, there would need to be a very high misdiagnosis rate for the stroke risk after sensory events to be similar to that of motor events. Fifth, rates of intracranial vascular imaging in our study were low (36\% of patients), and we were not therefore able to identify the subset of patients with capsular warning syndrome due to proximal middle cerebral artery stenosis. ${ }^{20,21}$

\section{AUTHOR CONTRIBUTIONS}

Nicola L.M. Paul: study concept and design, acquisition of data, draft and revision of the manuscript, statistical analysis and interpretation of data. Michela Simoni: revision of the manuscript content, acquisition of data. Arvind Chandratheva: revision of the manuscript content, acquisition of data. Professor Peter M Rothwell: study concept and design, draft and revision of the manuscript, analysis and interpretation of data, study supervision.

\section{DISCLOSURE}

N.L.M. Paul, M. Simoni, and A. Chandratheva report no disclosures. P.M. Rothwell is in receipt of an NIHR Senior Investigator Award and Wellcome Trust Senior Investigator Award. Go to Neurology.org for full disclosures.

Received December 29, 2011. Accepted in final form May 8, 2012.

\section{REFERENCES}

1. Giles MF, Rothwell PM. Substantial underestimation of the need for outpatient services for TIA and minor stroke. Age Ageing 2007;36:676-680.

2. Kleindorfer D, Panagos P, Pancioli A, et al. Incidence and short-term prognosis of transient ischemic attack in a population-based study. Stroke 2005;36:720-723.

3. Hill MD, Yiannakoulias N, Jeerakathil T, Tu JV, Svenson LW, Schopflocher DP. The high risk of stroke immediately after transient ischemic attack: a population-based study. Neurology 2004;62:2015-2020.

4. Johnston SC, Gress DR, Browner WS, Sidney S. Shortterm prognosis after emergency department diagnosis of TIA. JAMA 2000;284:2901-2906.

5. Lisabeth LD, Ireland JK, Risser JM, et al. Stroke risk after transient ischemic attack in a population-based setting. Stroke 2004;35:1842-1846.
6. Lovett JK, Dennis MS, Sandercock PA, Bamford J, Warlow CP, Rothwell PM. Very early risk of stroke after a first transient ischemic attack. Stroke 2003;34:138-140.

7. Rothwell PM, Giles MF, Flossmann E, et al. A simple score $(A B C D)$ to identify individuals at high early risk of stroke after transient ischaemic attack. Lancet 2005;366: 29-36.

8. Coull AJ, Lovett JK, Rothwell PM. Population based study of early risk of stroke after transient ischaemic attack or minor stroke: implications for public education and organisation of services. BMJ 2004;328:326-330.

9. Johnston SC, Rothwell PM, Nguyen-Huynh MN, et al. Validation and refinement of scores to predict very early stroke risk after transient ischaemic attack. Lancet 2007; 369:283-292.

10. Merwick A, Albers GW, Amarenco P, et al. Addition of brain and carotid imaging to the $\mathrm{ABCD} 2$ score to identify patients at high early stroke risk after transient ischaemic attack. Lancet Neurol 2010;1060-1069.

11. National Institute for Health and Clinical Excellence. The diagnosis and acute management of stroke and transient ischaemic attacks [online]. Available at: http://guidance.nice.org. uk/CG68.

12. Scottish Intercollegiate Guidelines Network. Management of patients with stroke: assessment, investigation, immediate and secondary prevention (SIGN 108) [online]. Available at: www.sign.ac.uk/pdf/sign 108.pdf.

13. Department of Health. National stroke strategy, 2007. Available at: http://www.dh.gov.uk/en/Publicationsand statistics/Publications/PublicationsPolicyandguidance/ dh_081062.

14. National Collaborating Centre for Chronic Conditions. Stroke: National Clinical Guideline for Diagnosis and Initial Management of Acute Stroke and Transient Ischaemic Attack (TIA). London: Royal College of Physicians; 2008.

15. Johnston SC, Nguyen-Huynh MN, Schwarz ME, et al. National Stroke Association Guidelines for the Management of Transient Ischemic Attacks. Ann Neurol 2006;60: 301-313.

16. The Stroke Prevention and Educational Awareness Diffusion (SPREAD) Collaboration. The Italian Guidelines for Stroke Prevention. Neurol Sci. 2006;21:5-12.

17. Gomman J, Barber PA, Fink J. Preventing strokes: the assessment and management of people with transient ischemic attack. N Z Med J 2009;122:3556-3567.

18. Donnan GA, O'Malley RN, Quang L, Hurley S, Bladin $\mathrm{PF}$. The capsular warning syndrome: pathogenesis and clinical features. Neurology 1993;43:957-962.

19. Hankey GJ, Warlow CP. Lacunar transient ischaemic attacks: a clinically useful concept. Lancet 1991;337:335338.

20. Yoon W, Seo J, Cho KH, et al. Symptomatic middle cerebral artery stenosis treated with intracranial angioplasty: experience in 32 patients. Radiology 2005;237:620-626.

21. Cho KH, Kang DW, Kwon SU, Kim JS. Location of single subcortical infarction due to middle cerebral artery atherosclerosis: proximal versus distal arterial stenosis. J Neurol Neurosurg Psychiatry 2009;48-52.

22. Rothwell PM, Coull AJ, Giles MF, et al. Change in stroke incidence, mortality, case-fatality, severity, and risk factors in Oxfordshire, UK from 1981 to 2004 (Oxford Vascular Study). Lancet 2004;363:1925-1933.

23. Rothwell PM, Coull AJ, Silver LE, et al. Population-based study of event-rate, incidence, case fatality, and mortality 
for all acute vascular events in all arterial territories (Oxford Vascular Study). Lancet 2005;366:1773-1783.

24. Coull AJ, Silver LE, Bull LM, Giles MF, Rothwell PM. Direct assessment of completeness of ascertainment in a stroke incidence study. Stroke 2004;35:2041-2045.

25. Adams HP Jr, Bendixen BH, Kappelle LJ, et al. Classification of subtype of acute ischemic stroke: definitions for use in a multicenter clinical trial: TOAST: Trial of Org 10172 in Acute Stroke Treatment. Stroke 1993;24:35-41.

26. Nakajima M, Hirano T, Naritomi H, Minematsu K. Symptom progression or fluctuation in transient ischaemic attack patients predicts subsequent stroke. Cerebrovasc Dis 2010;29:221-227.

27. Purroy F, Montaner J, Molina C, Delgado P, Ribo M, Alvarez-Sabin J. Patterns and predictors of early risk of recurrence after transient ischaemic attack with respect to aetiologic subtypes. Stroke 2007;38:3225-3229.

28. Johnston SC, Sidney S, Bernstein A, Gress D. A comparison of risk factors for recurrent TIA and stroke in patients diagnosed with TIA. Neurology 2003;60:280-285.

29. Kim SH, Han SW, Heo J. Predictive implications of recurrent transient ischaemic attacks in large artery atherosclerosis. Cerebrovasc Dis 2006;22:240-244.
30. Lovett JK, Coull A, Rothwell PM, Oxford Vascular Study. Early risk of recurrent stroke by aetiological subtype: implications for stroke prevention. Neurology 2004;62:569574.

31. Caporale CM, Notturno F, Caulo M, Uncini A. Capsular warning syndrome mimicking a jacksonian sensory march. J Neurol Sci 2009;262-264.

32. Teng T, Hong CT. Capsular warning syndrome: report of a case. Acta Neurol Taiwan 2008;17:248-252.

33. Vivanco-Hidalgo RM, Rodriguez-Campello A, Ois A, et al. Thrombolysis in capsular warning syndrome. Cerebrovasc Dis 2008;25:508-510.

34. Fahey CD, Alberts MJ, Bernstein RA. Oral clopidogrel load in aspirin-resistant capsular warning syndrome. Neurocrit Care 2005;2:183-184.

35. Lalive PH, Mayor I, Sztajzel R. The role of blood pressure in lacunar stroke preceded by TIAs. Cerebrovasc Dis 2003; 16:88-90.

36. Rothwell PM, Giles MF, Chandratheva A, et al. Effect of urgent treatment of transient ischemic attack and minor stroke on early recurrent stroke (EXPRESS study): a prospective population-based sequential comparison. Lancet 2007;370:1432-1442.

\section{Save These Dates for AAN CME Opportunities!}

Mark these dates on your calendar for exciting continuing education opportunities, where you can catch up on the latest neurology information.

Regional Conference

- October 26-28, 2012, Las Vegas, Nevada, Encore at Wynn Hotel

AAN Annual Meeting

- March 16-23, 2013, San Diego, California, San Diego Convention Center

\section{Refresh Your Annual Meeting Experience with New 2012 AAN On Demand}

- More than 600 hours of cutting-edge educational content and breakthrough scientific research

- Online access within 24 hours of end of program

- Mobile streaming for most iPad ${ }^{\circledR}$, iPhone ${ }^{\circledR}$, and Android ${ }^{\circledR}$ devices

- USB Flash Drive offers convenient offline access (shipped after the Annual Meeting)

- Enhanced browser, search, and improved interface for better overall experience

Get a great value with special pricing on AAN On Demand and the Syllabi on CD. Learn more at www.aan.com/view/ondemand2. 